\section{OPEN ACCESS}

Edited by:

Yuji Morita,

Aichi Gakuin University, Japan

Reviewed by:

Yaqi You,

Johns Hopkins University, USA

Vincent Sanchis,

Institut National de la Recherche

Agronomique, France

*Correspondence:

Christina S. Hölzel

c.hoelzel@/mu.de;

Shuangyang Ding

dingsy@cau.edu.cn

${ }^{\dagger}$ These authors have contributed equally to this work.

Specialty section:

This article was submitted to Infectious Diseases,

a section of the journal

Frontiers in Microbiology

Received: 22 December 2015 Accepted: 29 April 2016

Published: 23 May 2016

Citation:

Zhu K, Hölzel CS, Cui Y, Mayer R,

Wang $Y$, Dietrich $R$, Didier $A$,

Bassitta R, Märtlbauer E and Ding $S$

(2016) Probiotic Bacillus cereus

Strains, a Potential Risk for Public

Health in China.

Front. Microbiol. 7:718.

doi: 10.3389/fmicb.2016.00718

\title{
Probiotic Bacillus cereus Strains, a Potential Risk for Public Health in China
}

\author{
Kui Zhu ${ }^{1,2 \dagger}$, Christina S. Hölzel ${ }^{2 * \dagger}$, Yifang Cui ${ }^{3}$, Ricarda Mayer ${ }^{2}$, Yang Wang ${ }^{3}$, \\ Richard Dietrich ${ }^{2}$, Andrea Didier ${ }^{2}$, Rupert Bassitta ${ }^{2}$, Erwin Märtlbauer ${ }^{2}$ and \\ Shuangyang Ding ${ }^{3 *}$
}

${ }^{1}$ Beijing Advanced Innovation Center for Food Nutrition and Human Health, College of Veterinary Medicine, China Agricultural University, Beijing, China, ${ }^{2}$ Department of Veterinary Sciences, Ludwig Maximilian University of Munich, Oberschleißheim, Germany, ${ }^{3}$ National Center for Veterinary Drug Safety Evaluation, China Agricultural University, Beijing, China

Bacillus cereus is an important cause of foodborne infectious disease and food poisoning. However, B. cereus has also been used as a probiotic in human medicine and livestock production, with low standards of safety assessment. In this study, we evaluated the safety of 15 commercial probiotic $B$. cereus preparations from China in terms of mislabeling, toxin production, and transferable antimicrobial resistance. Most preparations were incorrectly labeled, as they contained additional bacterial species; one product did not contain viable $B$. cereus at all. In total, 18 B. cereus group strains-specifically $B$. cereus and Bacillus thuringiensis-were isolated. Enterotoxin genes nhe, hbl, and cytK1, as well as the ces-gene were assessed by PCR. Enterotoxin production and cytotoxicity were confirmed by ELISA and cell culture assays, respectively. All isolated $B$. cereus group strains produced the enterotoxin Nhe; 15 strains additionally produced Hbl. Antimicrobial resistance was assessed by microdilution; resistance genes were detected by PCR and further characterized by sequencing, transformation and conjugation assays. Nearly half of the strains harbored the antimicrobial resistance gene tet(45). In one strain, tet(45) was situated on a mobile genetic element-encoding a site-specific recombination mechanism - and was transferable to Staphylococcus aureus and Bacillus subtilis by electro-transformation. In view of the wide and uncontrolled use of these products, stricter regulations for safety assessment, including determination of virulence factors and transferable antimicrobial resistance genes, are urgently needed.

Keywords: Bacillus cereus, probiotic, enterotoxin, antimicrobial resistance, China, tetracycline resistance gene tet(45), site-specific recombination, dif site

\section{INTRODUCTION}

Bacillus cereus is a common cause of foodborne infectious disease: in a 10-year US survey B. cereus was ranked the fifth most common bacterial species causing foodborne outbreaks (http://www.cdc. gov/foodsafety/pdfs/fdoss-98-08-appendix-contributing-factors-508c.pdf; for detailed outbreak analysis see Bennett et al., 2013). Worldwide, Chinese food is frequently associated with foodborne B. cereus outbreaks (Notermans and Batt, 1998). Accordingly, B. cereus accounted for $13.4 \%$ of 1082 bacterial foodborne outbreaks between 1994 and 2005 in China; B. cereus was ranked 
as the second after Salmonella spp. amongst the most frequent bacterial causes of foodborne disease in Chinese inland provinces (Wang et al., 2007). This might be partly attributed to consumption habits, since $B$. cereus outbreaks are regularly associated with the consumption of rice (Ankolekar et al., 2009). In addition to rice (and pasta), meat, and dairy products are also important sources of foodborne $B$. cereus outbreaks in humans (Ruusunen et al., 2013; López et al., 2015). There are two different types of foodborne disease related to $B$. cereus: intoxication due to pre-formed cereulide or infection, followed by intra-intestinal production of enterotoxins such as Nhe and Hbl (Stenfors Arnesen et al., 2008). Foodborne B. cereus disease is generally self-limiting, although severe cases and even deaths have been reported (Bottone, 2010).

Though, being known as an important foodborne pathogen, $B$. cereus is licensed as a probiotic for men and livestock. In China, the safety of $B$. cereus probiotics is assessed and regulated; however, these regulations are partly rendered obsolete by recent research on $B$. cereus, particularly the identification of new virulence factors (Kim et al., 2015; Omer et al., 2015; Kilcullen et al., 2016). Thus, there is a lack of appropriate safety assessment for these probiotics in China-and also in other parts of the world-although, probiotics are even used to treat bacterial infections (Isolauri, 2003). In legal terms, probiotics are usually considered as supplements or foods-a fact which is critically discussed (Arnold, 2013). Apart from one pseudooutbreak (Kniehl et al., 2003), no case of foodborne B. cereus infection due to the use of probiotics has theretofore been reported. However, a fatal infection following the application of a probiotic Bacillus subtilis preparation was reported in an immune-compromised patient (Oggioni et al., 1998).

Probiotic strains are applied to livestock as well. Thus, the use of $B$. cereus probiotics in livestock production might provide an additional hazard for human health. In China, animal wastes are traditionally used as feed in fish ponds; this creates a melting pot for bacteria of human, animal, and environmental origin and thereby facilitates horizontal gene transfer (Allen et al., 2010). Thus, besides the lack of detectable toxicity, future probiotic safety regulations should take into account the potential of transferring antibiotic resistance genes.

We hypothesize that toxin production, transferable antimicrobial resistance, and contamination with other bacteria are important safety aspects of probiotics, but insufficiently assessed up to now. Therefore, we intended to re-evaluate these important safety parameters in commercial probiotic B. cereus products.

\section{MATERIALS AND METHODS}

\section{Isolation and Identification of Bacteria}

Products were collected between 2013 and 2015 from nine provinces in China (Table 1). This investigation included all four $B$. cereus preparations licensed for human use. From the original packaging, the capsules with the dried probiotic preparations were removed with a tweezer, dipped into $80 \%$ ethanol, flametreated and soaked in sterile distilled water until the capsules where dissolved. Subsequently, the content was suspended and
$0.1 \mathrm{ml}$ of the suspension was plated on Columbia agar with 5\% sheep blood (Oxoid, Wesel, Germany). Single colonies of each different phenotype were passaged on new agar plates. Matrix assisted laser desorption/ionization (MALDI-TOF) mass spectrometry was used for bacterial identification (Schulthess et al., 2014). Phenotypic identification by means of biochemical tests with the API $50 \mathrm{CH}$ and $20 \mathrm{E}$ kits (BioMerieux) were used to further confirm and/or characterize the B. cereus group bacteria. The total DNA of each isolate was extracted from overnight cultures in casein hydrolysate-yeast medium plus $1 \%$ glucose (CGY) using the DNeasy blood and tissue kit (Qiagen, Germany), according to the protocol for Gram-positive bacteria. An extended multiplex PCR assay with five pairs of universal primers was used to identify the cry-group genes in the Bacillus thuringiensis strains (Ben-Dov et al., 1997).

\section{Detection of Enterotoxins and Emetic Toxin}

The four main toxin genes of $B$. cereus, ces, nhe, hbl, and cytK1, were detected as previously described (Wehrle et al., 2009). Enzyme-linked immunosorbent assays were used to detect the production of $B$. cereus toxins, based on monoclonal antibodies specifically recognizing different epitopes of each toxin component (Zhu K. et al., 2013). Cytotoxicity assays were performed on Vero and HEp-2 cells to evaluate the toxic potential of the strains due to the production of enterotoxins (Nhe, Hbl, and CytK1) and/or emetic toxin (cereulide), respectively (Wehrle et al., 2009). B. cereus NVH 75/95, DSMZ 4384, and MHI 165 were used as reference strains for Nhe, $\mathrm{Hbl}$, and cereulide, respectively (Wehrle et al., 2009; Lindbäck et al., 2010). B. cereus NVH 391/98 served as reference strain for CytK1, with a variant nhe-gene and no expression of the Nhe complex in the bacterial culture medium (Fagerlund et al., 2007).

\section{Assessment of Phenotypic Antimicrobial Resistance}

Antimicrobial resistance was assessed by a standardized microdilution assay (ISO 20776-1:2006) in cation adjusted Mueller Hinton broth (CAMHB). The assay included ampicillin, amoxicillin + clavulanate, cefaclor, cefoxitin, cefuroxime, ciprofloxacin, clindamycin, colistin, daptomycin, doxycycline, enrofloxacin, ertapenem, erythromycin, florfenicol, fosfomycin, gentamicin, imipenem, linezolid, meropenem, oxacillin, penicillin, quinupristin + dalfopristin, rifampicin, streptomycin, teicoplanin, telithromycin, tobramycin, and vancomycin.

\section{Detection of Antimicrobial Resistance Genes}

The presence of the tetracycline resistance genes tet $(\mathrm{A})$, tet $(\mathrm{B})$, tet $(\mathrm{C})$, tet $(\mathrm{D}), \operatorname{tet}(\mathrm{K}), \operatorname{tet}(\mathrm{L}) / \operatorname{tet}(45)$, tet $(\mathrm{M})$, and $t e t(\mathrm{O})$ was assessed by end-point PCR as described elsewhere (Smith et al., 2004; Srinivasan et al., 2008; You et al., 2012); this selection included the most commonly detected tet-genes in Bacillus cereus (Agersø et al., 2002), but also four genestet(A), tet(B), tet(C), tet(D) - that were not yet found in the genus Bacillus (http://faculty.washington.edu/marilynr/tetweb3. pdf). PCR products were purified and submitted for sequencing (Sequiserve, Vaterstetten, Germany). The obtained sequences 
TABLE 1 | Characterization of commercial B. cereus containing probiotic products in China.

\begin{tabular}{|c|c|c|c|c|c|c|c|}
\hline Product No. & Strain No. & Origin & Label & Other species & Intended for use in & Species & Toxin type \\
\hline 1 & 1 & Jiangsu & mono & none & Human & B. cereus & Nhe, $\mathrm{Hbl}$ \\
\hline \multirow[t]{2}{*}{2} & $2 a$ & Jiangsu & mono & none $e^{\#}$ & & B. cereus & Nhe, Hbl \\
\hline & $2 b$ & & & & & B. cereus & Nhe \\
\hline 3 & 3 & Henan & mono & none & & B. cereus & Nhe, $\mathrm{Hbl}$ \\
\hline 4 & 4 & Zhejiang & mixed & not determined & & B. cereus & Nhe, Hbl \\
\hline 5 & $5 c$ & Jiangsu & mono & other Bacillus spp. & Animal & B. cereus & Nhe \\
\hline 6 & $6 f$ & Hebei & mono & $\begin{array}{l}\text { other Bacillus spp. } \\
\text { Acinetobacter sp. } \\
\text { Enterococcus sp. } \\
\text { no ID. }\end{array}$ & & B. cereus & Nhe, Hbl \\
\hline 7 & $7 d$ & Hebei & mono & other Bacillus spp. & & B. thuringiensis & Nhe, Hbl, Cry \\
\hline 8 & $8 \mathrm{~h}$ & Hebei & mixed & other Bacillus spp. & & B. cereus & Nhe, $\mathrm{Hbl}$ \\
\hline \multirow[t]{2}{*}{9} & $9 b$ & Hebei & mixed & $\begin{array}{l}\text { other Bacillus spp. } \\
\text { Staphylococcus } \\
\text { sp. } \\
\text { Pseudomonas sp. }\end{array}$ & & B. thuringiensis & Nhe, Hbl, Cry \\
\hline & $9 i$ & & & & & B. cereus & Nhe \\
\hline 10 & & Hebei & mixed & $\begin{array}{l}\text { other Bacillus spp. } \\
\text { Enterococcus sp. } \\
\text { Cronobacter sp. } \\
\text { Acinetobacter sp. }\end{array}$ & & none & \\
\hline 11 & 11 & Shandong & mono & none & & B. cereus & Nhe, Hbl \\
\hline 12 & $12 \mathrm{c}$ & Jiangxi & mixed & other Bacillus spp. & & B. cereus & Nhe, $\mathrm{Hbl}$ \\
\hline 13 & $13 d$ & Guangdong & mono & other Bacillus spp. & & B. cereus & Nhe, Hbl \\
\hline \multirow[t]{2}{*}{14} & $14 \mathrm{e}$ & Shanxi & mixed & other Bacillus spp. & Plant & B. cereus & Nhe, Hbl \\
\hline & $14 f$ & & & & & B. thuringiensis & Nhe, Hbl, Cry \\
\hline \multirow[t]{2}{*}{15} & $15 a$ & Hubei & mixed & other Bacillus spp. & & B. thuringiensis & Nhe, Hbl, Cry \\
\hline & $15 d$ & & & & & B. cereus & Nhe, Hbl \\
\hline
\end{tabular}

"Toxin type" refers to the detection of the corresponding gene in the PCR-assay plus positive ELISA-reaction at the level of the reference strains plus cytotoxicity for Vero-cells. \# two different $B$. cereus strains.

were compared with public databases (NCBI, EMBL-EBI) to verify the PCR products and to distinguish between tet $(\mathrm{L})$ and tet(45) (You et al., 2013).

\section{Transferability of Antimicrobial Resistance Transformation Assay Electro-transformation}

The spread of antimicrobial resistance genes was determined in a modified transferability test as described elsewhere (Zhu W. et al., 2013). Plasmids of the B. cereus strain 9i were extracted by QIAfilter Plasmid Midi Kit $\left(\right.$ QIAGEN $\left.^{\circledR}\right)$. Subsequently, $500 \mathrm{ng}$ of the purified plasmids were transformed into Staphylococcus aureus RN4220 electrocompetent cells, at $200 \Omega, 25 \mu \mathrm{Fd}, 2500 \mathrm{~V}$. After incubation at $37^{\circ} \mathrm{C}$ for $2 \mathrm{~h}$, the resulting transformants were spread on brain heart infusion (BHI) agar plates containing $16 \mathrm{mg} / \mathrm{L}$ tetracycline, and incubated at $37^{\circ} \mathrm{C}$ for another 24 to $48 \mathrm{~h}$. Isolated single colonies were tested for the presences of tet(45) by PCR assay, and the obtained PCR products were submitted for sequence analysis. Electro-transformation of B. subtilis ATCC 6051, Escherichia faecalis JH2-2, Bacillus licheniformis ATCC 14580 and Bacillus amyloliquefaciens ATCC 23842 followed the same protocol.

\section{Chemical transformation}

For the preparation of competent cells of B. subtilis ATCC 6051, B. subtilis was cultured on LB agar plates at $37^{\circ} \mathrm{C}$ for $24 \mathrm{~h}$; a single colony was inoculated in $5 \mathrm{~mL}$ GM1 medium and shaken at $100 \mathrm{rpm}\left(37^{\circ} \mathrm{C}\right)$ for $16 \mathrm{~h}$. Subsequently, $2 \mathrm{~mL}$ of $B$. subtilis culture was transferred to $18 \mathrm{~mL}$ GM1 medium and shaken at $100 \mathrm{rpm}\left(37^{\circ} \mathrm{C}\right)$ for another $3 \mathrm{~h}$. Ten milliliters of the culture was subsequently transferred into $90 \mathrm{~mL}$ GM2 medium and shaken at $100 \mathrm{rpm}\left(37^{\circ} \mathrm{C}\right)$ for $2 \mathrm{~h}$. Lastly, all the cells were collected after centrifugation at $4000 \mathrm{rpm}\left(4^{\circ} \mathrm{C}\right)$ for $10 \mathrm{~min}$ and re-suspended by $10 \mathrm{~mL} \mathrm{GM} 2$ medium with the addition of $5 \mathrm{~mL} 30 \%$ glycerol to prepare the competent cells of B. subtilis. Chemical transformation was performed with Escherichia coli (DH5 $\alpha$ ) and B. subtilis competent cells as recipients using 0.5-1 $\mu \mathrm{g}$ plasmid DNA extracted from the donor strain B. cereus $9 \mathrm{i}$, according to the manufacturer's instruction (TaKaRa).

\section{Conjugation Assay}

Filter matings were performed with E. coli (EC600, rifampin resistant), S. aureus (RN4220), E. faecalis (JH2-2, rifampin resistant), and B. subtilis (ATCC 6051) as the recipient strains, following the method described elsewhere (Huys et al., 2004). Overnight cultures of the donor (B. cereus $9 \mathrm{i}$ ) or recipient strains 
were diluted to $10^{8} \mathrm{CFU} / \mathrm{mL}$ in brain heart infusion (BHI) broth (Land Bridge Technology). Five microliters of each dilution was added into $1 \mathrm{~mL} \mathrm{BHI}$ broth and incubated at $37^{\circ} \mathrm{C}$ for $4 \mathrm{~h}$. The cultures of donor $(20 \mu \mathrm{L})$ and recipients $(60 \mu \mathrm{L})$ were mixed and filtered through a sterile $0.2 \mu \mathrm{m}$ membrane filter (Millipore), and placed at $37^{\circ} \mathrm{C}$ for overnight incubation. After mating, the colonies were washed with $1 \mathrm{~mL}$ BHI broth and plated on $\mathrm{BHI}$ agars, containing $8 \mu \mathrm{g} / \mathrm{mL}$ TET and further incubated at $37^{\circ} \mathrm{C}$ for $24 \mathrm{~h}$. For the selection of potential transconjugants, the agar plates contained $8 \mu \mathrm{g}$ TET /mL; for E. coli EC600 and E. faecalis $\mathrm{JH} 2-2,25 \mu \mathrm{g}$ rifampin /mL was added. Potential transformants grown on the selective agar plates were identified by $16 \mathrm{~S}$ rRNAgene sequences and tested for the presences of tet(45) by PCR assay.

\section{Genetic Environment of tet(45)}

The DNA of B. cereus 9i was extracted (Wizard Genomic DNA Purification Kit, Promega) and partially identified by high-throughput sequencing (Illumina Hiseq 2500, performed at BerryGenomics Inc., Beijing China). A preliminary draft assembly of the genomic fragments was conducted using CLC Genomics Workbench 5 (CLC Bio, Aarhus, Denmark).

Once the surrounding of tet(45) was known, we designed primer pairs targeting the upstream- and downstreamenvironment of tet(45): UP-tet(45) (fw: TGGTTGAAGAGG CACTCTATGG, rv: GGCGTAAATTTGACTGTGAATGA), tet(45)-INT1 (fw: TCATCGTCATTAGCTGGTTGGT, rv: AAG TTGCAGAGGACATGGAAAAAC), INT1-INT2 (fw: TTT TCGGGGTTGATGGGCAA, rv: CGATGAGGAAAAACATCG AGAATCA), INT2-HTH (fw: GCGTGGCTTGTCCTTTCT AAC, rv: AGAACCCCAACAAGACTCCC), in order to verify the environment of tet(45) in representatives of each different variant of tet(45). All PCR-reactions were performed with an initial denaturation of $5 \mathrm{~min}$ at $94^{\circ} \mathrm{C}, 35$ cycles of $60 \mathrm{~s}$ at $94^{\circ} \mathrm{C}$, $60 \mathrm{~s}$ at $54^{\circ} \mathrm{C}, 90 \mathrm{~s}$ at $72^{\circ} \mathrm{C}$, and a final elongation of $5 \mathrm{~min}$ at $72^{\circ} \mathrm{C}$. B. cereus 9 i served as positive control.

\section{RESULTS}

\section{Presence of Multiple Bacterial Species}

A total of 66 morphologically different strains were isolated from 15 typical samples labeled as products containing B. cereus in mono-preparation (Product No. 1-3, 5-7, 11, and 13) or mixed preparation (Product No. 4, 8-10, 12, 14, and 15). Based on bacterial morphology and biochemical testing results, as well as cry-gene based multiplex-PCR and MALDI-TOF mass spectrometry, these 66 isolates were classified as belonging to more than 10 different bacterial species; 18 strains were identified as belonging to the $B$. cereus group (Table 1 ). Four of these strains were further identified as B. thuringiensis due to the presence of the plasmid-borne $c r y$-genes encoding insecticidal crystal toxins $($ cry $1+$ cry $2+c r y 7 / 8$ in strains $9 \mathrm{~b}, 14 \mathrm{f}$, and $15 \mathrm{a}$; cry 2 in strain $7 \mathrm{~d})$. One sample (No. 10) did not contain viable B. cereus, but viable $B$. subtilis spores, instead. In total, this product contained nine different viable bacterial strains, including Cronobacter sakazakii and Acinetobacter baumannii.

\section{Detection of Toxins}

The PCR-assay detected $n h e$ in all isolated B. cereus group strains (Table 1); $h b l$ was detected in 15 isolates; accordingly, all strains were cytotoxic for Vero-cells. None of the isolates harbored cesgenes which are a hallmark of emetic strains, or cytK1. Enzymelinked immunosorbent assays confirmed that non-hemolytic enterotoxin (Nhe) and hemolysin $\mathrm{BL}(\mathrm{Hbl})$ were expressed by the $n h e$-/ $h b l$-positive strains at the levels of the respective positive controls.

\section{Antimicrobial Resistance}

Microdilution according to ISO-20776 indicated natural (species-specific) insusceptibility to penicillins (ampicillin, oxacillin, penicillin), cephalosporins (cefaclor, cefoxitin, cefuroxime), and colistin, as well as varying susceptibility for daptomycin, amoxicillin+clavulanate, and fosfomycin (Table 2). Microdilution further revealed eight isolates (44\%) with elevated MIC-values for doxycycline (1-4 mg/L) whereas all other isolates had MIC-values $\leq 0.125-0.25 \mathrm{mg}$ doxycycline /L. The same eight strains were positive for tet(45). Sequence analysis revealed that seven tet(45) amplicons were identical among each other, but the amplicon of the eighth strain, $9 i$, showed a different sequence (Figure 1).

\section{Plasmid Extraction and Horizontal Transfer}

Further investigations demonstrated that $B$. cereus $9 \mathrm{i}$ contained two plasmids, one of $\sim 10 \mathrm{kB}$ and one of $>50 \mathrm{kB}$ in size (Figure 2). Both plasmids were assumedly low copy plasmids, generating reproducible, but weak bands on agarose gel (Figure 2). The tet(45)-gene of 9i was successfully transferred into S. aureus RN4220 and B. subtilis ATCC6051 (but not E. coli) by electro-transformation. Transformed $S$. aureus and B. subtilis increased their doxycycline MIC-values from $\leq 0.25$ to $2 \mathrm{mg} / \mathrm{L}$. After electro-transformation, the tet(45)-gene was amplified in the DNA-extracts of the putative transformants. However, neither chemical transformation nor conjugation assays resulted in detectable transfer of tet(45).

\section{Genetic Environment of tet(45)}

Partial sequence analysis of the DNA extracts is visualized in Figure 3. The tet(45)-gene is located on a putatively mobile genetic element (MGE) of 6789 bp (Genbank accession number KX091844). Upstream, the MGE starts with a difSLlike binding motif (Figure 3) situated on a 413 bp sequence of unknown function, which precedes tet(45). Downstream, tet(45) is followed by a gene encoding a protein of unknown function. The insertion element further contains two different integrase genes $(2181 / 1347 \mathrm{bp})$ - at least one of the integrases with significant similarity to a site-specific tyrosine recombinase, XerS-and a 552 bp gene encoding a MerR superfamily protein (putative excisionase) with a helix-turn-helix domain.

With DNA-extracts of two representatives of the second tet(45)-variant, no amplicons were generated when we used primer pairs UP-tet(45), tet(45)-INT1, INT1-INT2, or INT2$\mathrm{HTH}$, while amplicons of the expected size were found for B. cereus 9i (positive control) in each PCR-reaction. 


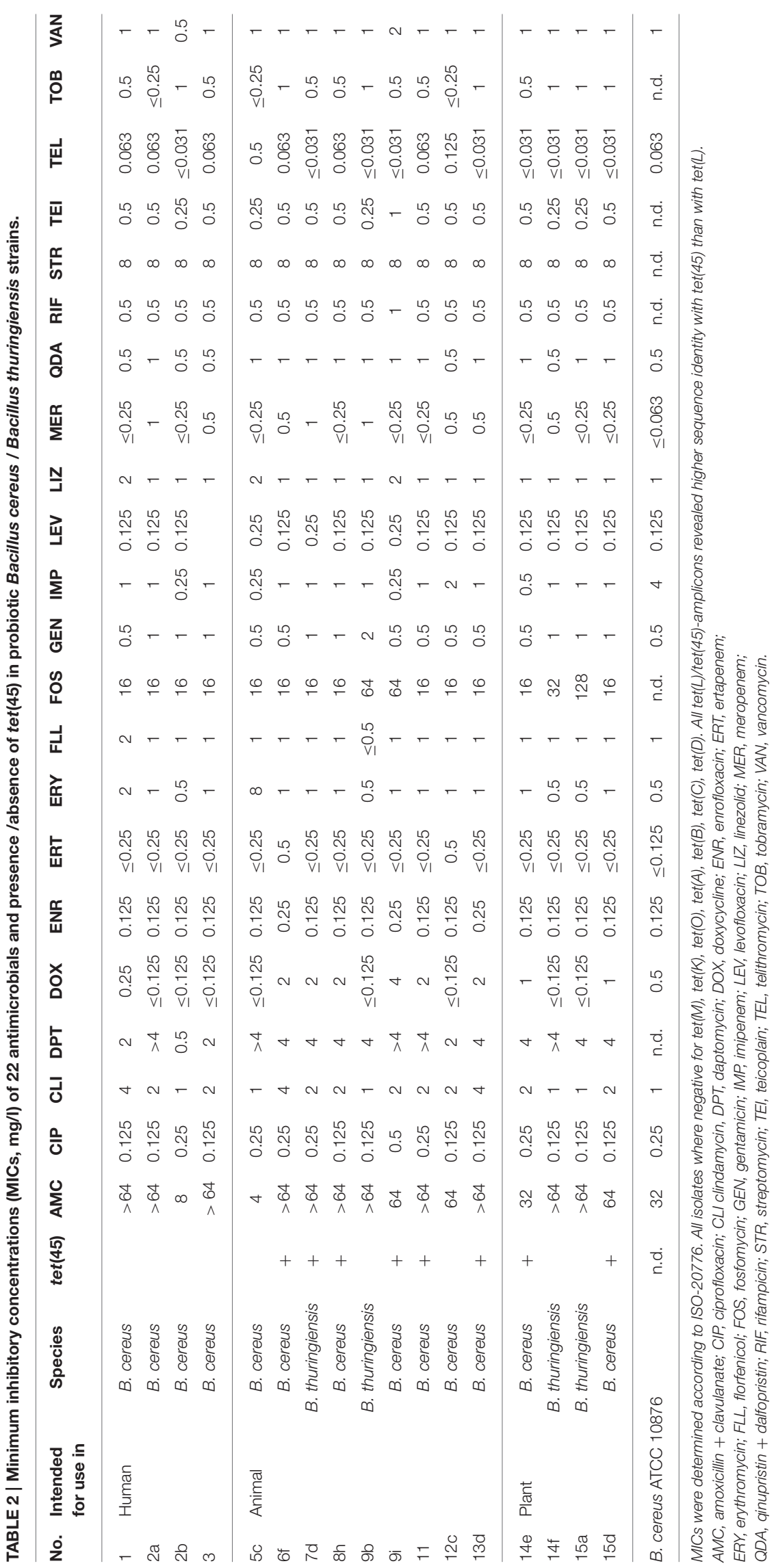




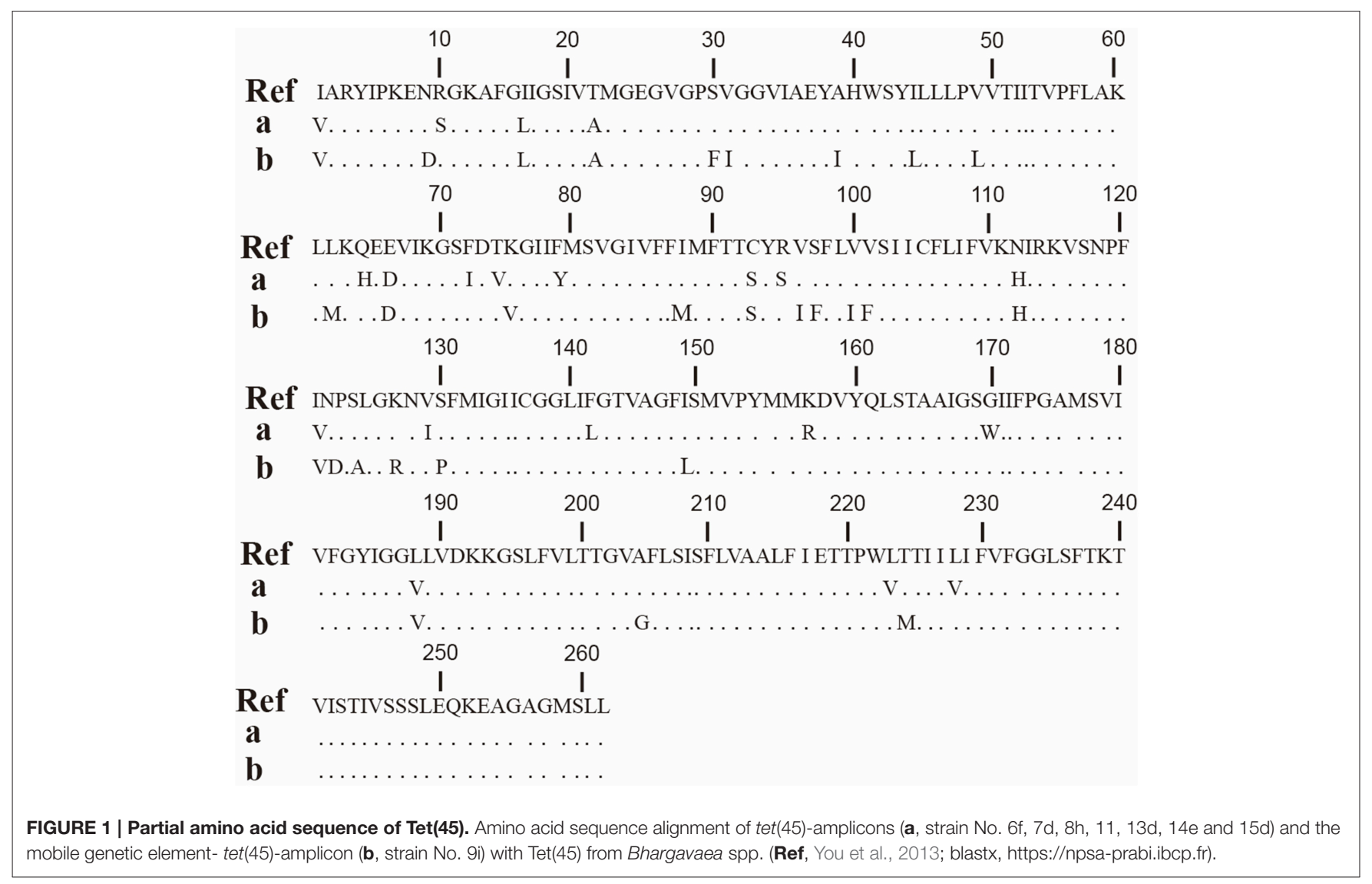

Sequences of the mobile genetic element and of the second tet(45) variant (partial sequence) were deposited in Genbank (accession numbers KX091844 and KX091845).

\section{DISCUSSION}

\section{Mislabeled Probiotic Products}

Five products labeled as $B$. cereus-monopreparations contained bacterial species which did not belong to the $B$. cereus group. Mislabeling of probiotic Bacillus strains is a common problem also observed in Europe, where Bactisubtil has been firstly labeled to contain B. subtilis spores instead of B. cereus spores (Huys et al., 2013). Vice versa, in our study one preparation for use in livestock did not contain any viable $B$. cereus group strain, but $B$. subtilis spores, instead. In addition, the product contained two opportunistic human pathogens, A. baumannii and C. sakazakii; the latter outnumbered the B. subtilis spores (data not shown).

\section{Toxins}

Due to the presence of plasmid-borne cry-group-genes, which encode insecticidal toxins, four strains were identified as $B$. thuringiensis. Two of them were isolated from preparations that were not labeled to contain $B$. thuringiensis. B. cereus is closely related to $B$. thuringiensis: the $16 \mathrm{~S}$ rRNA-gene sequences share more than 99\% similarity (Stenfors Arnesen et al., 2008). The insecticidal toxins of $B$. thuringinesis are not harmful for mammals; however, the isolates also produced enterotoxins ( $\mathrm{Hbl}$ and Nhe), as did all of the $B$. cereus group strains (Table 1 ). $\mathrm{Hbl}$ and Nhe are pore-forming toxins, each composed of three individual proteins, which show a specific order of binding to mammalian cells. Although the mode of action of these toxins is not fully understood, assembly of the components seems to occur partly in solution and is completed on the cell surface resulting in pore formation and cell lysis (Lindbäck et al., 2010; Sastalla et al., 2013). For both toxins, the presence of all three compounds is necessary to evoke toxicity, and only strains expressing complete $\mathrm{Hbl}$ and/or Nhe can be regarded as diarrheic (Stenfors Arnesen et al., 2008). This was the case for all isolated $B$. cereus group strains, the expression level of Nhe was even similar to the reference strain isolated from a food poisoning case in Norway (Lund and Granum, 1996; data not shown). A probiotic B. cereus strain licensed in the European Union has also been shown to produce biologically active enterotoxins (Nhe, Hbl; Duc et al., 2004). Interestingly, a preparation of this strain was withdrawn for use in animals, while still included in a licensed-but originally mislabeled-preparation for human use (Huys et al., 2013; Hong and Cutting, 2005).

\section{Enteropathogenic B. cereus}

The infectious dose of enteropathogenic $B$. cereus was proposed to be $1 \times 10^{5}$ to $1 \times 10^{8} \mathrm{CFU}$ or spores/g (Granum and Lund, 1997). Variations in this infectious dose are attributed to 


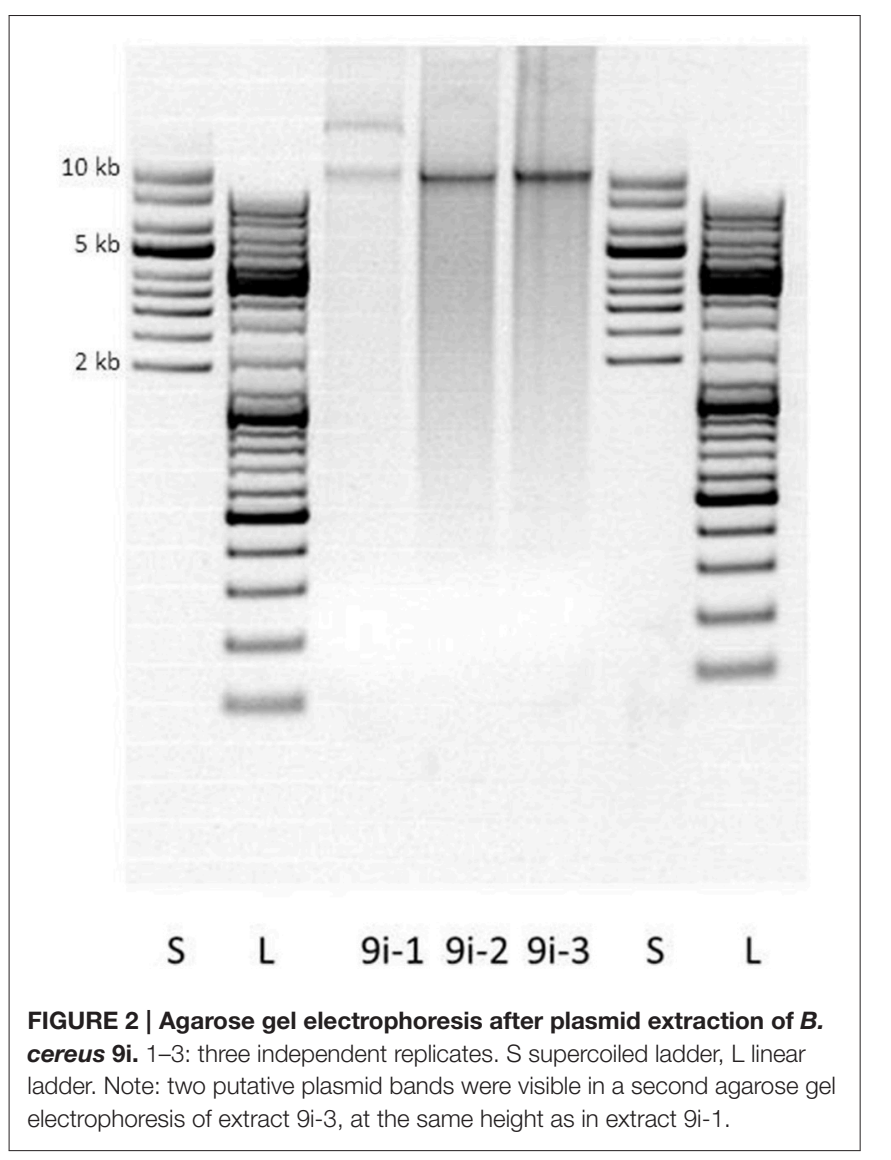

strain traits, since strains differ both in the amount of toxins produced (Dommel et al., 2011; Jessberger et al., 2015; Lücking et al., 2015), and also in their capability for intestinal persistence. Probiotic strains are applied in a dose of $10^{7}-10^{9} \mathrm{CFU}$ or spores/g; they have also been selected for their ability to colonize the intestinal tract (Duc et al., 2004). Thus, given their high likelihood to establish colonies in the intestine, unsafe probiotic strains might provide a major health risk, compared to strains casually ingested with food. Such health risks have been demonstrated in case studies. For example, a fatal infection with a probiotic Bacillus preparation in an immune-compromised patient has been reported (Oggioni et al., 1998).

\section{Transferable Antimicrobial Resistance Gene}

Besides the lack of toxicity, the presence of transferable resistance genes or not is another major safety parameter for probiotic strains. At least one of the strains investigated in the current study carried a tetracycline resistance gene, tet(45), on a mobile genetic element. In Bacillus spp., some corresponding entries in Genbank are labeled as "tetracycline resistance MFS efflux pump," which overcomes the problem that the protein encoded by tet(45) in Bacillus spp. is similar to the product of tet $(\mathrm{L})$ so that partial sequences might not allow unambiguous distinction. However, the complete sequence presented here has higher similarity to the reference sequences of tet(45) than to the reference sequences of tet(L) (http://faculty.washington.edu/marilynr/tetweb4.pdf).

The mobile element contained a difSL-like binding site, the tet(45)-gene, one ORF encoding a hypothetical protein, two integrase genes (one of the XerS superfamily, but without significant similarity to the XerS-encoding gene of Streptococcus suis), two non-coding-sequences of unknown function and a gene encoding a MerC-superfamily protein (putative excisionase). The coherent mobile element as found here was not described in Bacillus spp. before, but NCBIBLAST revealed 93\% identity to an inverse sequence of B. cereus MSX-D12 (pos. 2856985-2851281), isolated 2005 in the Antarctic Concordia Station by Timmery et al. (2011). At $5^{\prime}$, the putative MGE in 9i begins with an adenin-rich-motif (caaaaaagaatcc). This motif was identified as the "left-hand" part of a putative Xer-binding/cleavage site, since the $3^{\prime}$ ("right-half")site (tattaaaaggacag) downstream the motif had remarkably high identity to difSL (Leroux et al., 2011; bold = consensus), whereas the sequence had much lower similarity to known Xer-binding sites of Bacillus spp. (e.g., cer, dif, difBS). MSX-D12 presented a complementary difSL-like sequence at $3^{\prime}$ (Figure 3).

The sequence situated upstream of the putative MGE in 9i contains one single caaaaaagaatcctg-cag-motif; an inverted repeat of the motif, gattctttttg (missing the cag-sequence which is adhered at the $5^{\prime}$ cleavage site), follows immediately downstream of the $3^{\prime}$ end of the MGE. In MSX-D12, the samebut undisrupted-sequence is situated $\sim 2,100,000$ bp upstream of the putative mobile element described here, forming a perfect $30 \mathrm{bp} \quad$ palindrome (caaaaagaatcctg\|caggattcttttttg). Interestingly, the both opposed ends of the palindrome are identical to the opposed ends of the "left-hand"-part of difSL (Leroux et al., 2011).

Identical upstream and downstream genes-encoding a YdcFlike protein and an S-layer protein-are found in MSX-D12 (not shown), NC7401 and 9i (Figure 3, respectively) next to both ends of the palindromic cleavage site. This raises strong suspicion that, in $9 \mathrm{i}$, tet(45) was inserted into this sequence by help of (and together with) the site-specific recombinases encoded downstream. In MSX-D12, the MGE was inserted at another palindromic site (Figure 3), was inversely orientated, and its insertion was accompanied by a crossover-event so that the palindromic sequence at both ends of the MGE was directly mirrored (tattttcttttttcttag $\|$ gattctttttctttttat) instead of being complimentary.

Remarkably, while the binding site had high homology with the difSL-site identified in Streptococcus and Lactococcus, the XerS-like protein had no significant similarity with the XerSproteins of Streptococcus or Lactococcus, and two different integrase genes were combined in the MGE, hinting toward a XerC/XerD-like dimeric process of site-specific recombination instead of a "stand-alone" mechanism as proposed for XerS (Leroux et al., 2011).

B. cereus $9 \mathrm{i}$ contained two plasmids. However, in the plasmid extracts we could neither identify any gene associated with conjugation, nor did we succeed in transferring tet(45) by means of conjugation assays. The YdcF-like-protein and the S-layer-protein which are connected by the putative insertion 


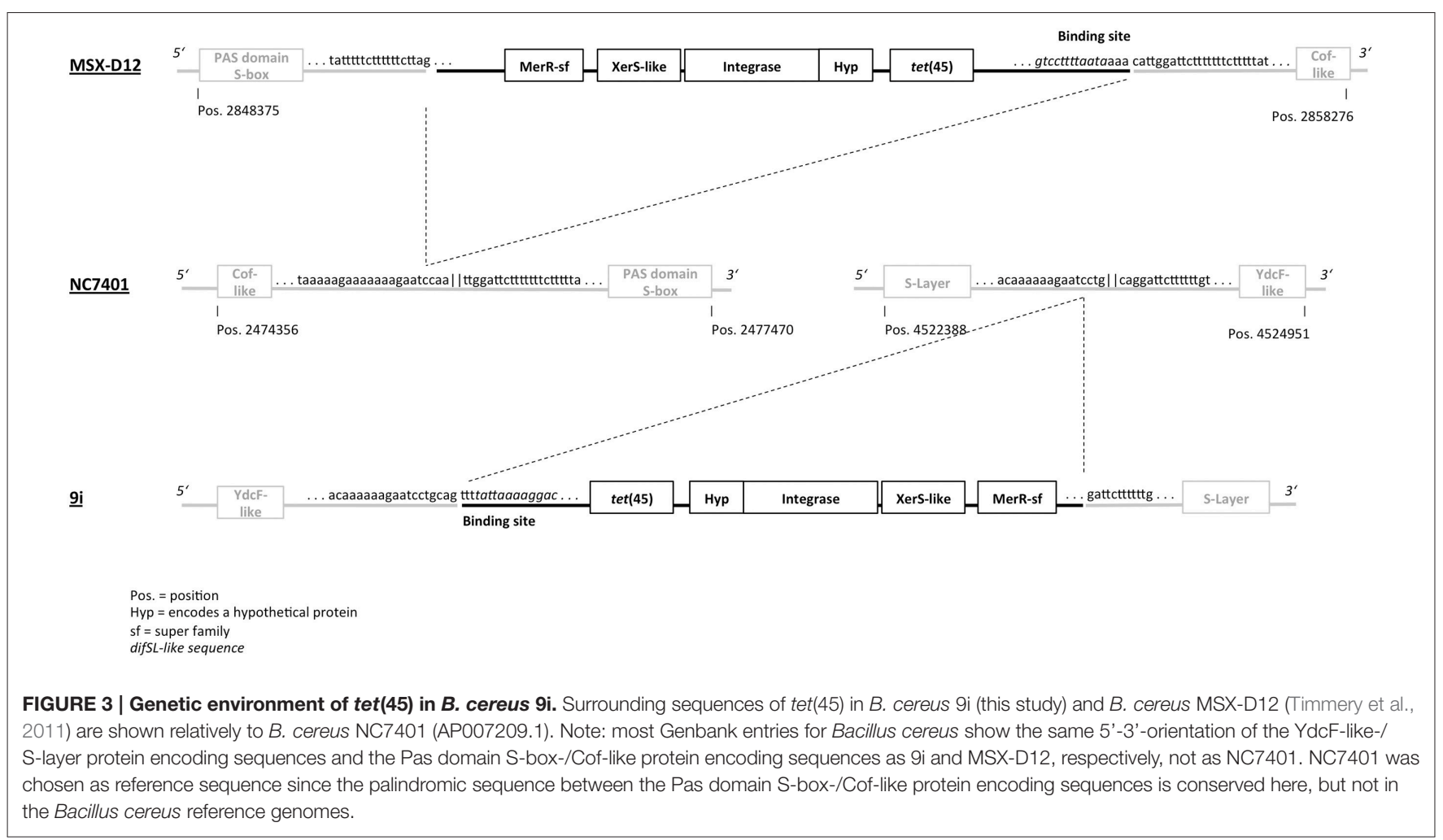

site are chromosomally encoded in Bacillus spp. This does not necessarily mean that tet(45) is chromosomally integrated in 9i, since chromosomal genes could also be transferred to plasmids, as vice versa. Very recently (2016-03-21) there was a new Genbank entry of a B. thuringiensis plasmid (pBT1850294, CP014284.1) which encodes a significantly similar pair of integrase genes (66\% nucleotide identity). However, we assume that the transfer of tet(45) to S. aureus and B. subtilis was not necessarily associated with its presence on one of the two plasmids found in $9 \mathrm{i}$, but was associated with a small mobile genetic element, instead. Such elements could be easily integrated into naturally competent hosts after natural transformation, especially if insertion relies on conserved integrases like the Xer-superfamily (Midonet and Barre, 2014), as indicated here. The difSL-like "right-hand"-motif is present in the genome of a variety of other bacteria, e.g., Lawsonia intracellularis (e.g., CP004029.1), Mycoplasma spp. (e.g., CP014346.1), Clostridia spp. (e.g., CP011803.1), A. baumannii (e.g., CP014528.1), Staphylococcus spp. (e.g., KT780704), and other Bacillus spp. (e.g., CP012600.1). While it is unknown whether these bacteria express recombinase enzymes that bind there, at least streptococci and lactococci are known to do so. Moreover, Aneurinibacillus soli (AP017312.1) and B. mycoides (CP007626.1) encode a pair of integrases (and also a MerC-superfamily protein) with significant similarity to the recombinase enzymes described here, suggesting a further possibility for interspecific and even intergeneric transfer of the MGE.

The detection of a mobile tet(45)-gene in probiotics is certainly undesirable. Due to the presence of a tetracycline resistance gene located on a mobile genetic element, together with insufficient data on toxicity, the probiotic $B$. cereus strain of Esporafeed Plus has been considered unsafe for use as a feed additive for calves and pigs in Europe in 1999 (http://ec.europa. eu/food/fs/sc/scan/out39_en.pdf, accessed March 31, 2016); more recently, Bacillus toyonensis was considered unsafe for use in chickens, pigs, cattle and rabbits for the same reason (http:// www.efsa.europa.eu/en/efsajournal/pub/3766, accessed May 12, 2016). The tet(45)-gene has been originally detected in an environmental bacterium, Bhargavaea spp., from which it was successfully transferred to E. coli (You et al., 2012). Many antibiotic resistance genes (ARGs) of common human pathogenic bacteria are assumed to originate from environmental bacterial communities (Martínez, 2008; Forsberg et al., 2012). As a spore-forming bacterium and original soil inhabitant, $B$. cereus has a distinct ability to persist in and (re-)adapt to the environment (Carlin et al., 2010). Therefore, it cannot be ruled out that mobile resistance determinants may be further transferred to other soil bacteria, but also to other animal or human pathogens after excretion of such probiotic $B$. cereus strains. The detection of tet $(\mathrm{M})$-carrying $B$. cereus in soil was directly related to manure application in the past (Agersø et al., 2002; Roberts, 2012). In view of the wide and uncontrolled use of probiotics, strict regulations are urgently needed to decrease the probability of transfer of ARGs and safety assessment of these products must include the determination of antimicrobial resistance profiles.

Here, we summarize the possible health hazards of commercial probiotic products advertised to contain B. cereus in 
China due to mislabeling, toxin production and the presence of transferable antimicrobial resistance. The growing presence of pharmaceutical and biotechnological companies has contributed to an increase of $B$. cereus related products, but these products are often of poor quality and incorrectly designated. It must be emphasized that the safety of these commercially available probiotics is not a limited local public health issue in China, but may also be relevant worldwide due to global trade and international travel.

\section{AUTHOR CONTRIBUTIONS}

$\mathrm{KZ}, \mathrm{EM}$, and SD conceived the project. $\mathrm{KZ}, \mathrm{CH}, \mathrm{YC}, \mathrm{RM}, \mathrm{YW}$, $\mathrm{AD}, \mathrm{RD}, \mathrm{RB}$, and $\mathrm{SD}$ conceived and performed experiments

\section{REFERENCES}

Agersø, Y., Jensen, L. B., Givskov, M., and Roberts, M. C. (2002). The identification of a tetracycline resistance gene tet $(\mathrm{M})$, on a Tn916-like transposon, in the Bacillus cereus group. FEMS Microb. Lett. 214, 251-256. doi: 10.1016/S03781097(02)00883-2

Allen, H., Donato, J., Wang, H., Cloud-Hansen, K., Davies, J., and Handelsman, J. (2010). Call of the wild: antibiotic resistance genes in natural environments. Nat. Rev. Microbiol. 8, 251-259. doi: 10.1038/nrmicro2312

Ankolekar, C., Rahmati, T., and Labbé, R. (2009). Detection of toxigenic Bacillus cereus and Bacillus thuringiensis spores in US rice. Int. J. Food Microbiol. 128, 460-466. doi: 10.1016/j.ijfoodmicro.2008.10.006

Arnold, C. (2013). The pros and cons of probiotics. Lancet Infect. Dis. 7, 571-572. doi: 10.1016/S1473-3099(13)70172-5

Ben-Dov, E., Zaritsky, A., Dahan, E., Barak, Z., Sinai, R., Manasherob, R., et al. (1997). Extended screening by PCR for seven cry-group genes from field-collected strains of Bacillus thuringiensis. Appl. Environ. Microbiol. 63, 4883-4890.

Bennett, S., Walsh, K., and Gould, H. (2013). Foodborne disease outbreaks caused by Bacillus cereus, Clostridium perfringens, and Staphylococcus aureus-United States, 1998-2008. Clin. Infect. Dis. 57, 425-433. doi: 10.1093/cid/cit244

Bottone, E. (2010). Bacillus cereus, a volatile human pathogen. Clin. Microbiol. Rev. 23, 382-398. doi: 10.1128/CMR.00073-09

Carlin, F., Brillard, J., Broussole, V., Clavel, T., Duport, C., Jobin, M., et al. (2010). Adaptation of Bacillus cereus, an ubiquitous worldwide-distributed foodborne pathogen, to a changing environment. Food Res. Int. 43, 1885-1894. doi: 10.1016/j.foodres.2009.10.024

Dommel, M., Lücking, G., Scherer, S., and Ehling-Schulz, M. (2011). Transcriptional kinetic analyses of cereulide synthetase genes with respect to growth, sporulation and emetic toxin production in Bacillus cereus. Food Microbiol. 28, 284-290. doi: 10.1016/j.fm.2010.07.001

Duc, L., Hong, H., Barbosa, T., Henriques, A., and Cutting, S. (2004). Characterization of Bacillus probiotics available for human use. Appl. Environ. Microbiol. 70, 2161-2171. doi: 10.1128/AEM.70.4.2161-2171.2004

Fagerlund, A., Brillard, J., Fürst, R., Guinebretière, M. H., and Granum, P. E. (2007). Toxin production in a rare and genetically remote cluster of strains of the Bacillus cereus group. BMC Microbiol. 7:43. doi: 10.1186/1471-2180-7-43

Forsberg, K., Reyes, A., Wang, B., Selleck, E., Sommer, M., and Dantas, G. (2012). The shared antibiotic resistome of soil bacteria and human pathogens. Science 337, 1107-1111. doi: 10.1126/science.1220761

Granum, P., and Lund, T. (1997). Bacillus cereus and its food poisoning toxins. FEMS Microbiol. Lett. 157, 223-228. doi: 10.1111/j.1574-6968.1997.tb12776.x

Hong, H., and Cutting, S. (2005). The use of bacterial spore formers as probiotics. FEMS Microbiol. Rev. 29, 813-835. doi: 10.1016/j.femsre.2004.12.001

Huys, G., Botteldoorn, N., Delvigne, F., De Vuyst, L., Heyndrickx, M., Pot, B., et al. (2013). Microbial characterization of probiotics-advisory report of the Working Group "8651 Probiotics" of the Belgian Superior Health Council (SHC). Mol. Nutr. Food Res. 57, 1479-1504. doi: 10.1002/mnfr.201300065 and/or data analysis. $\mathrm{CH}, \mathrm{KZ}, \mathrm{EM}$, and SD wrote the manuscript, $\mathrm{RB}$ conceived the graphical design. $\mathrm{KZ}$ and $\mathrm{CH}$ contributed equally to this work.

\section{ACKNOWLEDGMENTS}

We thank G. Acar, S. Eberhardt, S. Strassner, and B. Fritz for expert technical assistance. We thank S. Ulrich, Chair of Food Safety, and G. Wolf, Chair of Bacteriology, LMU Munich, for performing the MALDI-TOF-analysis. This study is supported by the National Basic Research Program of China (2013CB127200), Special Fund for Agro-Scientific Research in the Public Interest (201203069-2) and Fund of Modern Agriculture Industry System Innovation in Beijing City Team (1051-25012090).

Huys, G., D'Haene, K., Collard, J., and Swings, J. (2004). Prevalence and molecular characterization of tetracycline resistance in Enterococcus isolates from food. Appl. Environ. Microbiol. 70, 1555-1562. doi: 10.1128/AEM.70.3.15551562.2004

Isolauri, E. (2003). Probiotics for treating infectious diarrhoea. Gut 52, 436-437. doi: 10.1136/gut.52.3.436

Jessberger, N., Krey, V., Rademacher, C., Böhm, M., Mohr, A., Ehling-Schulz, M., et al. (2015). From genome to toxicity: a combinatory approach highlights the complexity of enterotoxin production in Bacillus cereus. Front. Microbiol 6:560. doi: 10.3389/fmicb.2015.00560

Kilcullen, K., Teunis, A., Popova, T. G., and Popov, S. G. (2016). Cytotoxic potential of Bacillus cereus strains ATCC 11778 and 14579 against human lung epithelial cells under microaerobic growth conditions. Front. Microbiol. 7:69. doi: 10.3389/fmicb.2016.00069

Kim, M., Han, J., Park, J., Lee, J., Lee, S., Cho, J., et al. (2015). Various enterotoxin and other virulence factor genes widespread among Bacillus cereus and Bacillus thuringiensis strains. J. Microbiol. Biotechnol. 25, 872-879. doi: 10.4014/jmb.1502.02003

Kniehl, E., Becker, A., and Forster, D. (2003). Pseudo-outbreak of toxigenic Bacillus cereus isolated from stools of three patients with diarrhoea after oral administration of a probiotic medication. J. Hosp. Infect. 55, 33-38. doi: 10.1016/S0195-6701(03)00133-6

Leroux, M., Jia, F., and Szatmari, G. (2011). Characterization of the Streptococcus suis XerS recombinase and its unconventional cleavage of the difSL site. FEMS Microbiol. Lett. 324, 135-141. doi: 10.1111/j.1574-6968.2011.02398.x

Lindbäck, T., Hardy, S. P., Dietrich, R., Sodring, M., Didier, A., Moravek, M., et al. (2010). Cytotoxicity of the Bacillus cereus Nhe enterotoxin requires specific binding order of its three exoprotein components. Infect. Immun. 78, 3813-3821. doi: 10.1128/IAI.00247-10

López, A., Minnaard, J., Pérez, P., and Alippi, A. (2015). A case of intoxication due to a highly cytotoxic Bacillus cereus strain isolated from cooked chicken. Food Microbiol. 46, 195-199. doi: 10.1016/j.fm.2014.08.005

Lücking, G., Frenzel, E., Rütschle, A., Marxen, S., Stark, T. D., Hofmann, T., et al. (2015). Ces locus embedded proteins control the non-ribosomal synthesis of the cereulide toxin in emetic Bacillus cereus on multiple levels. Front. Microbiol. 6:1101. doi: 10.3389/fmicb.2015.01101

Lund, T., and Granum, P. (1996). Characterisation of a non-haemolytic enterotoxin complex from Bacillus cereus isolated after a foodborne outbreak. FEMS Microbiol. Lett. 141, 151-156.

Martínez, J. L. (2008). Antibiotics and antibiotic resistance genes in natural environments. Science 321, 365-367. doi: 10.1126/science. 1159483

Midonet, C., and Barre, F. X. (2014). Xer site-specific recombination: promoting vertical and horizontal transmission of genetic information. Microbiol. Spectr. 2. doi: 10.1128/microbiolspec.MDNA3-0056-2014

Notermans, S., and Batt, C. (1998). A risk assessment approach for food-borne Bacillus cereus and its toxins. Symp. Ser. Soc. Appl. Microbiol. 27, 51S-61S. doi: 10.1046/j.1365-2672.1998.0840s151s.x 
Oggioni, M., Pozzi, G., Valensin, P., Galieni, P., and Bigazzi, C. (1998). Recurrent septicemia in an immunocompromised patient due to probiotic strains of Bacillus subtilis. J. Clin. Microbiol. 36, 325-326.

Omer, H., Alpha-Bazin, B., Brunet, J.-L., Armengaud, J., and Duport, C. (2015). Proteomics identifies Bacillus cereus EntD as a pivotal protein for the production of numerous virulence factors. Front. Microbiol. 6:1004. doi: 10.3389/fmicb.2015.01004

Roberts, M. C. (2012). "Mechanisms of bacterial antibiotic resistance and lessons learned from environmental tetracycline-resistant bacteria," in Antimicrobial Resistance in the Environment, 1st Edn., eds P. Keen and M. H. H. M. Montforts (Hoboken, NJ: John Wiley \& Sons), 93-122.

Ruusunen, M., Salonen, M., Pulkkinen, H., Huuskonen, M., Hellström, S., Revez, J., et al. (2013). Pathogenic bacteria in Finnish bulk tank milk. Foodborne Pathog. Dis. 10, 99-106. doi: 10.1089/fpd.2012.1284

Sastalla, I., Fattah, R., Coppage, N., Nandy, P., Crown, D., Pomerantsev, A. P., et al. (2013). The Bacillus cereus $\mathrm{Hbl}$ and Nhe tripartite enterotoxin components assemble sequentially on the surface of target cells and are not interchangeable. PLOS ONE 8:e76955. doi: 10.1371/journal.pone. 0076955

Schulthess, B., Bloemberg, G., Zbinden, R., Böttger, E., and Hombach, M. (2014). Evaluation of the Bruker MALDI Biotyper for identification of Gram-positive rods-development of a diagnostic algorithm for the clinical laboratory. J. Clin. Microbiol. 52, 1089-1097. doi: 10.1128/JCM. 02399-13

Smith, M., Yang, R., Knapp, C., Niu, Y., Peak, N., Hanfelt, M., et al. (2004). Quantification of tetracycline resistance genes in feedlot lagoons by real-time PCR. Appl. Environ. Microbiol. 70, 7372-7377. doi: 10.1128/AEM.70.12.73727377.2004

Srinivasan, V., Nam, H., Sawant, A., Headrick, S., Nguyen, L., and Oliver, S. (2008). Distribution of tetracycline and streptomycin resistance genes and class 1 integrons in Enterobacteriaceae isolated from dairy and nondairy farm soils. Microb. Ecol. 55, 184-193. doi: 10.1007/s00248-007-9266-6

Stenfors Arnesen, L., Fagerlund, A., and Granum, P. (2008). From soil to gut: Bacillus cereus and its food poisoning toxins. FEMS Microbiol. Rev. 32, 579-606. doi: 10.1111/j.1574-6976.2008.00112.x
Timmery, S., Hu, X., and Mahillon, J. (2011). Characterization of Bacilli isolated from the confined environments of the Antarctic Concordia station and the International Space Station. Astrobiol 11, 323-334. doi: 10.1089/ast.2010.0573

Wang, S., Duan, H., Zhang, W., and Li, J. (2007). Analysis of bacterial foodborne disease outbreaks in China between 1994 and 2005. FEMS Immunol. Med. Microbiol. 51, 8-13. doi: 10.1111/j.1574-695X.2007.00305.x

Wehrle, E., Moravek, M., Dietrich, R., Bürk, C., Didier, A., and Märtlbauer, E. (2009). Comparison of multiplex PCR, enzyme immunoassay and cell culture methods for the detection of enterotoxinogenic Bacillus cereus. J. Microbiol. Methods 78, 265-270. doi: 10.1016/j.mimet.2009.06.013

You, Y., Hilpert, M., and Ward, M. (2012). Detection of a common and persistent tet(L)-carrying plasmid in chicken-waste-impacted farm soil. Appl. Environ. Microbiol. 78, 3203-3213. doi: 10.1128/AEM.07763-11

You, Y., Hilpert, M., and Ward, M. (2013). Identification of Tet45, a tetracycline efflux pump, from a poultry-litter-exposed soil isolate and persistence of tet(45) in the soil. J. Antimicrob. Chemother. 68, 1962-1969. doi: 10.1093/jac/dkt127

Zhu, K., Dietrich, R., Didier, A., Acar, G., and Märtlbauer, E. (2013). Versatile antibody-sensing Boolean logic for the simultaneous detection of multiple bacterial toxins. Chem. Commun. 49, 9314-9316. doi: 10.1039/c3cc45370g

Zhu, W., Clark, N., and Patel, J. (2013). pSK41-like plasmid is necessary for Inc18-like vanA plasmid transfer from Enterococcus faecalis to Staphylococcus aureus in vitro. Antimicrob. Agents Chemother. 57, 212-219. doi: 10.1128/AAC. 01587-12

Conflict of Interest Statement: The authors declare that the research was conducted in the absence of any commercial or financial relationships that could be construed as a potential conflict of interest.

Copyright (C) 2016 Zhu, Hölzel, Cui, Mayer, Wang, Dietrich, Didier, Bassitta, Märtlbauer and Ding. This is an open-access article distributed under the terms of the Creative Commons Attribution License (CC BY). The use, distribution or reproduction in other forums is permitted, provided the original author (s) or licensor are credited and that the original publication in this journal is cited, in accordance with accepted academic practice. No use, distribution or reproduction is permitted which does not comply with these terms. 